\title{
3 Research Soure \\ Prognostic Significance of TM4SF1 and DDR1 Expression in Ovarian Cancer
}

\author{
Zhijiong Huang \\ Guangxi Medical University https://orcid.org/0000-0001-5868-2137 \\ Hongyu Yao \\ Guangxi Medical University affiliated Cancer Hospital \\ Zhijun Yang ( $\nabla$ yzj7528@126.com ) \\ Guangxi Medical University Cancer Hospital
}

Research

Keywords: Ovarian cancer, TM4SF1, DDR1, coexpression

Posted Date: September 17th, 2021

DOI: https://doi.org/10.21203/rs.3.rs-880151/v1

License: (1) This work is licensed under a Creative Commons Attribution 4.0 International License. Read Full License 


\section{Abstract}

Background: TM4SF1 and DDR1 are expressed in many cancers, but their expression in ovarian cancer and the relationship between their expression and patient prognosis are still unclear. The present study aimed to explore the expression of TM4SF1 and DDR1 as well as their relationship with the prognosis of ovarian cancer.

Methods: The Oncomine database and gene expression profile interactive analysis (GEPIA) were used to compare the different expression levels of TM4SF1 and DDR1 in ovarian cancer, and Kaplan-Meier plotter was used to analyse the relationship between gene expression and patient prognosis. The interacting proteins of TM4SF1 and DDR1 were analysed by STRING, which is an online protein interaction analysis tool, and enrichment analysis of Gene Ontology (GO) and Kyoto Encyclopaedia of Genes and Genomes (KEGG) pathways was conducted for these interacting proteins. Immunohistochemical staining was performed to detect the expression of TM4SF1 and DDR1 protein in ovarian cancer tissue and to analyse the relationship between the expression and prognosis.

Results: Database and clinical sample analyses showed that the expression levels of TM4SF1 and DDR1 were significantly higher in ovarian cancer and that TM4SF1 and DDR1 were coexpressed in some cases. STRING analysis found that the TM4SF1 and DDR1 proteins had an interaction relationship. The overall survival (OS) and progression-free survival (PFS) of ovarian cancer patients with TM4SF1 and DDR1 coexpression were significantly shorter than those of patients lacking TM4SF1 and DDR1 coexpression. Multivariate analysis showed that TM4SF1 and DDR1 protein coexpression was an independent prognostic factor.

Conclusions: TM4SF1 and DDR1 proteins were coexpressed in some ovarian cancer tissues and were considered adverse prognostic factors for ovarian cancer. Our findings suggested that there might be an interaction or mutual regulatory mechanism of TM4SF1 and DDR1.

\section{Introduction}

Ovarian cancer is one of the three common malignant tumours of the female reproductive system. The mortality rate of ovarian cancer ranks first among gynaecological malignancies, and the 5-year survival rate is only approximately $40 \%[1,2]$. Ovarian cancer cells are highly invasive, and widespread metastasis of the pelvis, abdominal cavity and retroperitoneal lymph nodes can occur in the early stage. Even if ovarian cancer patients receive standard treatment, approximately $70 \%$ of patients still experience recurrence, metastasis and drug resistance within 2 years, posing a serious threat to women's lives and health.

Transmembrane $4 \mathrm{~L}$ six family member 1 (TM4SF1) is a distant relative of the four-transmembrane protein superfamily. TM4SF1 is highly expressed in a variety of epithelial cancer tissues, and it regulates intracellular calcium levels, tyrosine phosphorylation and protein kinase $C[3,4]$. In addition, TM4SF1 is involved in the formation of vascular endothelial pseudopodia and angiogenesis, and it plays an important role in the regulation of cell development, activation, growth and movement [5]. It has been reported that overexpression of TM4SF1 in a variety of epithelial cancer tissues is associated with poor prognosis [6-9]. Discoidin domain receptor 1 (DDR1) is a member of the discoid domain receptor in the receptor tyrosine kinase family, and abnormally activated DDR 1 is related to the occurrence and development of tumours. Significantly higher expression of DDR1 exists in many types of malignant tumours [10], such as breast cancer, non-small-cell lung cancer, gastric cancer and colorectal cancer, and DDR1 is regarded as an adverse prognostic factor [11-14]. Similar to TM4SF1, DDR1 is critical in tumour cell survival, drug resistance, self-renewal, differentiation, adhesion and migration, and it participates in the regulation of tumour progression and metastasis [15]. 
According to previous studies, TM4SF1 and DDR1 interact with and activate resting cancer cells in distant organs to cause tumour recurrence and metastasis [16], but the relationship between the expression of TM4SF1 and DDR1 in ovarian cancer prognosis is still unclear. Therefore, the present study investigated the expression of TM4SF1 and DDR1 in ovarian cancer and their correlation with the prognosis of ovarian cancer.

\section{Materials And Methods}

\section{Patients and tissue samples}

Patients were treated at the Department of Gynaecological Oncology of Guangxi Medical University Affiliated Cancer Hospital from January 2013 to June 2017. All patients received ovarian tumour cytoreductive surgery and adjuvant chemotherapy. All cases were confirmed by pathological diagnosis, and complete clinicopathological parameters were obtained, including age, hospitalization time, operation time, operation method, degree of surgical resection, ascites, tumour pelvic metastasis, abdominal cavity metastasis, distant metastasis, histopathological type, degree of differentiation, tumour staging, adjuvant chemotherapy regimen, adjuvant chemotherapy frequency, recurrence and survival after treatment. The follow-up data were obtained by telephone or outpatient visits. The present study was approved by the Ethics Committee of Guangxi Medical University Affiliated Cancer Hospital.

\section{Immunohistochemistry (IHC) staining}

Paraffin-embedded ovarian cancer tissues were obtained from the Department of Pathology of Guangxi Medical University Affiliated Cancer Hospital. The tissues were cut into $4 \mu \mathrm{m}$ thick paraffin sections and heated at $60^{\circ} \mathrm{C}$ for $20 \mathrm{~min}$. The sections were then soaked in xylene and different concentrations of alcohol (95\%, 70\% and 50\%) for dewaxing followed by soaking in distilled water for $5 \mathrm{~min}$ for hydration. The hydrated tissue sections were immersed in a container with $0.01 \mathrm{M}$ citrate buffer $\left(\mathrm{pH}\right.$ 6.0) and heated to $92-98{ }^{\circ} \mathrm{C}$ for $10-115$ min for antigenic repair. According to the protocol, the two-step SP immunohistochemistry kit (Beijing Zhongshan Jinbridge) was used for the immunohistochemical detection of TM4SF1 and DDR1 expression in normal ovarian epithelium, benign ovarian tumour tissue and ovarian cancer tissue. The rabbit anti-human TM4SF1 antibody was purchased from Abcam (ab113504), and the rabbit anti-human DDR1 antibody was purchased from Cell Signaling Technology (\#5583). The antibodies were diluted at 1:100 and then developed in 3,3'-diaminobenzidine solution. The immunostained tissue sections were independently observed by two experienced pathologists on an optical microscope (Olympus, Japan) and were scored according to methods previously reported in the literature [17].

\section{GEPIA analysis}

GEPIA is a newly developed interactive online analysis tool (http://gepia.cancer-pku. cn/), and we used GEPIA to analyse the RNA sequencing expression data of 9736 tumour tissues from The Cancer Genome Atlas (TCGA) and 8587 normal tissues from the Genotype-Tissue Expression (GTEx) database [18]. In the present study, GEPIA was used to determine the expression levels of the TM4SF1 and DDR1 genes in different cancer types, and the differential expression of the TM4SF1 and DDR1 genes in ovarian cancer tissue and normal ovarian tissue was compared. Survival analysis of OS and DFS was then conducted to compare TM4SF1 and DDR1 expression in ovarian cancer patients. The hazard ratio $(\mathrm{HR})$ and $\mathrm{P}$ or Cox $\mathrm{P}$ values of the logarithmic rank test were calculated and displayed in the graph.

\section{Oncomine analysis}


Oncomine is currently the world's largest oncogene chip database and integrated data mining platform \https://www.oncomine.org $\rrbracket$, collecting 715 gene expression datasets and 86,733 cancer tissue and normal tissue samples $[19,20]$. First of all, we searched with "TM4SF1" and "DDR1" as keywords, and the results were displayed and set as: "P-value: 0.01", "Fold Change: 1.5" and "Gene Rank: all" to analyze the differential expressions of TM4SF1 and DDR1 in different types of tumors and corresponding normal tissues. Then, "TM4SF1" and "DDR1" were used as keywords, and "Ovarian Cancer", " Cancer vs. Normal " and "mRNA" data types were used as filter conditions, and the meta-analysis provided by Oncomine database was used to verify the differential expression of TM4SF1 and DDR1 genes in ovarian cancer tissue.

\section{PPI network}

STRING (version 11.0) is an online search tool for analysing protein-protein interactions and functional protein networks, and it contains confirmed and predicted direct and indirect protein-protein interaction biological data [21]. In the present study, TM4SF1 and DDR1 were used as query conditions, and the minimum required interaction score was set to above 0.4 of medium reliability. The top 50 proteins interacting directly with TM4SF1 and DDR1 were queried according to the interaction score.

\section{Functional and pathway enrichment analyses}

Using the R ClusterProfiler program package, TM4SF1, DDR1 and the top 50 filtered interacting proteins that directly interact with TM4SF1 and DDR1 were used to perform GO function and KEGG pathway enrichment analyses [22]. The GO functional enrichment analysis included the following three categories: biological process (BP), cell composition (CC) and molecular function (MF). A corrected $\mathrm{P}$ value of $<0.05$ was considered statistically significant.

\section{Kaplan-Meier (KM) plotter database analysis}

KM plotter is an online database that assesses the relationship of 54,000 genes in 21 cancer types with survival rates [23]. The relationships of TM4SF1 expression, DDR1 expression and combined TM4SF1 and DDR1 expression with OS and PFS in ovarian cancer were analysed.

\section{Statistical analysis}

Functional enrichment analysis was performed by R 3.63 software (https://www.r-project.org/). The clusterProfiler program package was used to perform GO and KEGG enrichment analyses, and enrichplot and ggplot2 program packages were used to visualize the enrichment analysis results.

\section{Results}

\section{Expression of TM4SF1 and DDR1 in cancers}

The biological functions and roles of TM4SF1 and DDR1 in cancer are still unclear. To reveal their roles in tumorigenesis and development, differentially expressed genes were identified. The results showed that TM4SF1 and DDR1 were highly expressed in a variety of common malignant tumours (Figure 1). GEPIA analysis showed that TM4SF1 and DDR1 were significantly higher in ovarian cancer than in normal ovaries (both P凶0.05). A meta-analysis of the Oncomine database (including 10 analyses of 7 ovarian cancer datasets) also showed that TM4SF1 and DDR1 were significantly more highly expressed in ovarian cancer than in normal ovarian tissue (TM4SF1: $P=0.004$; DDR1: $P=3.22 E-4)$ as shown in Figure 2. 


\section{Enrichment analysis of TM4SF1- and DDR1-interacting proteins}

The top 50 proteins that directly interact with TM4SF1 and DDR1 were queried by the STRING online tool, and 28 and 25 proteins were found to interact with TM4SF1 and DDR1, respectively. Among these interacting proteins, both CYSTM1 and NT5M interacted with TM4SF1 and DDR1, and TM4SF1 also interacted with DDR1 (Figure 3).

GO enrichment analysis of the interacting proteins showed that they were mainly involved in the composition of ECM, collagen, integrin and their complexes as well as adhesion spots, endoplasmic reticulum and other intracellular and extracellular components. GO enrichment analysis also indicated that these interacting proteins had the molecular function of binding with integrin, cell adhesion molecules, growth factors, proteoglycans, neurotrophic factor receptors and $\mathrm{y}$-catenin. $\mathrm{GO}$ analysis also showed that they were mainly involved in cell-matrix adhesion and cell response to amino acid stimulation, and it indicated that they played biological functions by activating integrin and collagen-mediated signalling pathways (Figure 4A, Supplementary Table 1). KEGG enrichment analysis showed that these interacting proteins were mainly involved in adhesion spot-related signal transmission, ECM-receptor interaction, actin cytoskeleton regulation, small RNA signalling pathways related to cancer, proteoglycan signalling pathways related to cancer, the PI3K/Akt signalling pathway, neurotrophic factor signalling pathways and a variety of tumour-related pathways, such as small cell lung cancer-, chronic myeloid leukaemia-, thyroid cancer- and bladder cancer-related pathways (Figure 4B, Supplementary Table 2).

\section{Expression of TM4SF1 and DDR1 proteins in ovarian cancer and the relation with clinicopathologic features}

A total of 94 patients with epithelial ovarian cancer were included, and the patient age ranged from 28 to 83 years old with a median age of 51 years. A total of 56 patients received neoadjuvant chemotherapy. The results showed that 46 patients (48.94\%) were positive for TM4SF1 protein, and 52 patients $(55.32 \%)$ were positive for DDR1 protein. In addition, 26 patients $(27.66 \%)$ were positive for both TM4SF1 and DDR1 protein. The staining of TM4SF1 and DDR1 proteins in ovarian cancer tissues is shown in Figure 5. Correlation analysis showed that only the positive expression of DDR1 protein was significantly different in different histological grades, FIGO stages and intraperitoneal metastases (both $\mathrm{P} \otimes 0.05$, Table 1).

\section{Relationship of TM4SF1 and DDR1 expression with the prognosis of ovarian cancer}

Biological database analysis showed that ovarian cancer patients with high expression of TM4SF1 had significantly lower disease-free survival(DFS) or PFS than those with low expression (DFS: $H R=1.3, P=0.046, n=424$, Figure 6A; PFS: $H R=1.17, P=0.019, N=1435$, Figure $6 E$ ). In addition, the expression of DDR1 had no correlation with patient DFS or PFS, and the expression of TM4SF1 and DDR1 had no significant correlation with patient OS (Figure 6B-D, Figure 6F-H). However, KM plotter multigene analysis showed that higher expression of TM4SF1 and DDR1 was significantly associated with shorter PFS of patients with ovarian cancer $(H R=1.15, P=0.039, n=1435$, Figure 6I) but not with OS (Figure 6J).

Analysis of clinical data showed that 94 patients had ovarian cancer with a median follow-up of 33 months, and there was no significant difference in the median OS between TM4SF1-positive and TM4SF1-negative patients (29 vs. 47 months, $P>0.05$ ). In contrast, the median OS of DDR1-positive patients was significantly shorter than that of DDR1-negative patients ( 31 vs. $>73$ months, $\mathrm{P}<0.05$ ). The median OS of patients with TM4SF1 and DDR1 coexpression was significantly shorter than that of patients lacking TM4SF1 and DDR1 coexpression (21 vs. 49 months, $\mathrm{P}<0.05$ ). In addition, the median PFS of TM4SF1-positive patients was significantly shorter than that of TM4SF1-negative patients (18 vs. 26 months, $P<0.05$ ). The median PFS of patients with TM4SF1 and DDR1 
coexpression was significantly shorter than that of patients lacking TM4SF1 and DDR1 coexpression (12 vs. 26 months, $\mathrm{P}<0.05)$, while the expression of DDR1 was not related to the median PFS ( $>0.05)$ (Figure 7$)$. Thus, the TM4SF1 and DDR1 coexpression indicated that patients with ovarian cancer had shorter PFS and OS.

\section{Analysis of prognostic factors in ovarian cancer}

Regarding the clinicopathological factors, univariate analysis showed that FIGO stage, intraperitoneal invasion, DDR1 expression, TM4SF1 expression and coexpression of DDR1 and TM4SF1 were factors affecting the OS of patients with ovarian cancer, while FIGO stage, lymph node resection and coexpression of TM4SF1 and DDR1 were factors affecting the PFS of ovarian cancer patients (Table 2).

Cox multivariate analysis showed that TM4SF1 and DDR1 coexpression was the only independent risk factor affecting OS and PFS in ovarian cancer patients (FIG. 8A, B), suggesting that the expression of TM4SF1 and DDR1 may be synergistically involved in the development of ovarian cancer.

\section{Discussion}

Ovarian cancer is a highly malignant gynaecological tumour. Despite the development of treatment methods, the prognosis of patients is still far from ideal. However, the pathogenesis of ovarian cancer is still unclear, and few effective therapeutic targets are available. TM4SF1 and DDR1 proteins have been reported to be expressed in a variety of cancer tissues and are associated with poor prognosis in patients [6-9,15], and database analysis has also reported similar results. However, the role of TM4SF1 and DDR1 in the occurrence, development and prognosis of ovarian cancer remains unclear.

Antitumour immunity induced by TM4SF1 inhibits the growth and migration of TM4SF1-positive cancer cells in vitro and in vivo [24]. Previous studies have found that the positive rate of TM4SF1 protein in ovarian cancer tissues, especially metastatic lymph nodes, is significantly higher than that in benign ovarian tumours and normal ovarian tissues. The expression status of TM4SF1 in ovarian cancer is significantly related to FIGO staging and tissue differentiation [25]. Similarly, our study also found that the positive rate of TM4SF1 protein in ovarian cancer tissues was higher, but it was slightly lower than that previously reported. This difference may be due to some cases with neoadjuvant chemotherapy and some stale specimens as well as different experimental conditions, sample sizes and operators. Among the related factors that affect the prognosis of patients, the PFS of TM4SF1-positive patients was significantly shorter than that of TM4SF1-negative patients but did not affect the OS of patients. Our study illuminated that the positive expression of TM4SF1 was not an independent risk factor for PFS and OS in ovarian cancer. In view of the difference in the positive rate of TM4SF1 compared to previous studies, the effect of neoadjuvant chemotherapy on the tissue expression of TM4SF1 requires further research to confirm.

DDR1 has different effects on the biological functions, disease progression and prognosis of different types of tumour cells, but increasing evidence has shown that it is involved in prometastatic and prosurvival signals [26]. Although DDR1 was not an independent risk factor affecting the prognosis of ovarian cancer, univariate analysis showed that it was significantly related to OS. Our study found that the positive rate of DDR1 in ovarian cancer tissues was $55.32 \%$, while the positive expression rate in patients with advanced stage (stages III to IV), low differentiation (or high grade) and peritoneal metastasis was significantly higher than that in patients with early stage (stages I to II), well differentiated tissues and nonperitoneal metastasis. Advanced stage and high-grade cancer are both poor prognostic factors for ovarian cancer. DDR1 was highly expressed in these sample types in our study, suggesting that DDR1 overexpression is positively correlated with the severity of the disease and that high 
pathological grade affects the OS of patients. Our results were consistent with previous results reported by Quan et al. [27], implying that DDR1 might play a role in promoting the survival and metastasis of ovarian cancer cells.

The immunohistochemical staining of ovarian cancer tissue sections showed that TM4SF1 and DDR1 proteins were mainly distributed in the cell membrane and that both were expressed in some cases. STRING analysis showed that there was an interaction between TM4SF1 and DDR. Moreover, the coexpression of M4SF1 and DDR1 was not only significantly related to PFS and OS in patients with ovarian cancer but was also an independent poor prognostic factor. Therefore, TM4SF1 and DDR1 might play important biological functions through interaction. Gao et al. [16] found that TM4SF1 interacts with DDR1 in breast cancer cells and that collagen I promotes their interaction and reactivation of dormant metastatic breast cancer cells in multiple organs, leading to breast cancer recurrence and multiple organ metastasis. Due to the limitation of immunostaining, whether TM4SF1 and DDR1 proteins are colocalized and interact with each other in ovarian cancer cells and whether a mutual regulatory mechanism between TM4SF1 and DDR exists remain to be further studied.

The present study reported the relationship of the combined expression of TM4SF1 and DDR1 with the prognosis of ovarian cancer patients. However, there were several limitations. First, there was not enough clinical samples, and the individual differences may have impacted the experimental results. Second, the tissue specimen quality, experimental operations and statistical errors may have affected the experimental results. Our research mainly focused on clinical studies, and further studies need to be conducted on the relevant regulatory mechanisms of TM4SF1 and DDR1 in ovarian cancer cells at the protein, cell function and animal levels.

\section{Conclusion}

The TM4SF1 and DDR1 proteins were coexpressed in some ovarian cancer tissues, which may be adverse prognostic factors for ovarian cancer patients, and there may be an interaction or mutual regulatory mechanism between TM4SF1 and DDR1.

\section{Abbreviations}

GEPIA: Gene Expression Profiling Interactive Analysis; GO: Gene Ontology; STRING: Search Tool for the Retrieval of Interacting Genes/Proteins; KEGG: Kyoto Encyclopaedia of Genes and Genomes; OS: Overall survival; PFS: progression-free survival ; TM4SF1:Transmembrane $4 \mathrm{~L}$ six family member 1; DDR1:Discoidin domain receptor 1; TCGA: The Cancer Genome Atlas; GTEx: The Genotype-Tissue Expression; DFS: Disease-free survival; KM: KaplanMeier; ECM: Extracellular matrix; PPI: Protein-protein interaction.

\section{Declarations}

\section{Acknowledgements}

We are thankful to the American Journal Experts for English language editing.

\section{Authors' contributions}

Zhijiong Huang and Hongyu Yao carried out the study concepts, literature research, clinical studies, data analysis, experimental studies, manuscript writing and editing; Zhijun Yang performed the study design, experimental instruction and manuscript modification. All authors have read and approved the submission of the manuscript.

Page $7 / 20$ 


\section{Funding}

This work was supported by grants from the National Natural Science Foundation of China (No.81360387》 No.82060476), the Guangxi Natural Science Foundation (No.2017GXNSFDA198009), the Guangxi Zhuang Autonomous Region Key Clinical Specialty Construction Project (2018-39), the Guangxi medical high-level backbone personnel training "139" Project (2018-22) and the Special Fund of the 17th Guangxi New Century "Ten, Hundred, Thousand" Talent Project (No.2014210).

\section{Availability of data and materials}

The data that support the findings of this study are not publicly available due to their containing information that could compromise the privacy of research participants but are available on request from the corresponding author.

Ethics approval and consent to participate

All patients signed the written informed consent. All procedures were approved by the Ethics Committee of Guangxi Medical University Cancer Hospital and operated in keeping with the standards set out in the Announcement of Helsinki and Laboratory Guidelines of Research in China.

\section{Consent for publication}

Not applicable.

\section{Competing interests}

All authors have no conflicts of interest and declare that we do not have any commercial or associative interest that represents a conflict of interest in connection with the work submitted.

\section{References}

1. Jelovac D, Armstrong DK. Recent progress in the diagnosis and treatment of ovarian cancer. CA Cancer J Clin. 2011; 61: 183-203.

2. Jacobs IJ, Menon U, Ryan A, Gentry-Maharaj A, Burnell M, Kalsi JK, Amso NN, Apostolidou S, Benjamin E, Cruickshank D, Crump DN, Davies SK, Dawnay A, Dobbs S, Fletcher G, Ford J, Godfrey K, Gunu R, Habib M, Hallett R, Herod J, Jenkins H, Karpinskyj C, Leeson S, Lewis SJ, Liston WR, Lopes A, Mould T, Murdoch J, Oram D, Rabideau DJ, Reynolds K, Scott I, Seif MW, Sharma A, Singh N, Taylor J, Warburton F, Widschwendter M, Williamson K, Woolas R, Fallowfield L, McGuire AJ, Campbell S, Parmar M, Skates SJ. Ovarian cancer screening and mortality in the UK Collaborative Trial of Ovarian Cancer Screening (UKCTOCS): a randomised controlled trial. Lancet. 2016; 387: 945-56.

3. Stipp CS, Kolesnikova TV, Hemler ME. Functional domains in tetraspanin proteins. Trends Biochem Sci. 2003; 28: 106-12.

4. Sciuto TE, Merley A, Lin Cl, Richardson D, Liu Y, Li D, Dvorak AM, Dvorak HF, Jaminet SC. Intracellular distribution of TM4SF1 and internalization of TM4SF1-antibody complex in vascular endothelial cells. Biochem Biophys Res Commun. 2015; 465: 338-43.

5. Hemler ME. Tetraspanin proteins mediate cellular penetration, invasion, and fusion events and define a novel type of membrane microdomain. Annu Rev Cell Dev Biol. 2003; 19: 397-422. 
6. Xing P, Dong H, Liu Q, Zhao T, Yao F, Xu Y, Chen B, Zheng X, Wu Y, Jin F, Li J. Upregulation of transmembrane 4 L6 family member 1 predicts poor prognosis in invasive breast cancer: A STROBE-compliant article. Medicine (Baltimore). 2017; 96: e9476.

7. Park YR, Lee ST, Kim SL, Liu YC, Lee MR, Shin JH, Seo SY, Kim SH, Kim IH, Lee SO, Kim SW. MicroRNA-9 suppresses cell migration and invasion through downregulation of TM4SF1 in colorectal cancer. Int J Oncol. 2016; 48: 2135-43.

8. Cao R, Wang G, Qian K, Chen L, Ju L, Qian G, Wu CL, Dan HC, Jiang W, Wu M, Xiao Y, Wang X. TM4SF1 regulates apoptosis, cell cycle and ROS metabolism via the PPARgamma-SIRT1 feedback loop in human bladder cancer cells. Cancer Lett. 2018; 414: 278-93.

9. Cao J, Yang JC, Ramachandran V, Arumugam T, Deng DF, Li ZS, Xu LM, Logsdon CD. TM4SF1 Regulates Pancreatic Cancer Migration and Invasion In Vitro and In Vivo. Cell Physiol Biochem. 2016; 39: 740-50.

10. Vogel W, Gish GD, Alves F, Pawson T. The discoidin domain receptor tyrosine kinases are activated by collagen. Mol Cell. 1997; 1: 13-23.

11. Peretti M, Badaoui M, Girault A, Van Gulick L, Mabille MP, Tebbakha R, Sevestre H, Morjani H, Ouadid-Ahidouch $\mathrm{H}$. Original association of ion transporters mediates the ECM-induced breast cancer cell survival: Kv10.1-Orai1SPCA2 partnership. Sci Rep. 2019; 9: 1175.

12. Yang SH, Baek HA, Lee HJ, Park HS, Jang KY, Kang MJ, Lee DG, Lee YC, Moon WS, Chung MJ. Discoidin domain receptor 1 is associated with poor prognosis of non-small cell lung carcinomas. Oncol Rep. 2010; 24: 311-9.

13. Hu Y, Liu J, Jiang B, Chen J, Fu Z, Bai F, Jiang J, Tang Z. MiR-199a-5p loss up-regulated DDR1 aggravated colorectal cancer by activating epithelial-to-mesenchymal transition related signaling. Dig Dis Sci. 2014; 59: 2163-72.

14. Jin H, Ham IH, Oh HJ, Bae CA, Lee D, Kim YB, Son SY, Chwae YJ, Han SU, Brekken RA, Hur H. Inhibition of Discoidin Domain Receptor 1 Prevents Stroma-Induced Peritoneal Metastasis in Gastric Carcinoma. Mol Cancer Res. 2018; 16: 1590-600.

15. Gadiya M, Chakraborty G. Signaling by discoidin domain receptor 1 in cancer metastasis. Cell Adh Migr. 2018; 12: 315-23.

16. Gao H, Chakraborty G, Zhang Z, Akalay I, Gadiya M, Gao Y, Sinha S, Hu J, Jiang C, Akram M, Brogi E, Leitinger B, Giancotti FG. Multi-organ Site Metastatic Reactivation Mediated by Non-canonical Discoidin Domain Receptor 1 Signaling. Cell. 2016; 166: 47-62.

17. Stierer M, Rosen H, Weber R, Hanak H, Spona J, Tuchler H. Immunohistochemical and biochemical measurement of estrogen and progesterone receptors in primary breast cancer. Correlation of histopathology and prognostic factors. Ann Surg. 1993; 218: 13-21.

18. Tang Z, Li C, Kang B, Gao G, Li C, Zhang Z. GEPIA: a web server for cancer and normal gene expression profiling and interactive analyses. Nucleic Acids Res. 2017; 45: W98-w102.

19. Rhodes DR, Yu J, Shanker K, Deshpande N, Varambally R, Ghosh D, Barrette T, Pandey A, Chinnaiyan AM. Largescale meta-analysis of cancer microarray data identifies common transcriptional profiles of neoplastic transformation and progression. Proc Natl Acad Sci U S A. 2004; 101: 9309-14.

20. Rhodes DR, Kalyana-Sundaram S, Mahavisno V, Varambally R, Yu J, Briggs BB, Barrette TR, Anstet MJ, KinceadBeal C, Kulkarni P, Varambally S, Ghosh D, Chinnaiyan AM. Oncomine 3.0: genes, pathways, and networks in a collection of 18,000 cancer gene expression profiles. Neoplasia. 2007; 9: 166-80.

21. Szklarczyk D, Gable AL, Lyon D, Junge A, Wyder S, Huerta-Cepas J, Simonovic M, Doncheva NT, Morris JH, Bork P, Jensen LJ, Mering CV. STRING v11: protein-protein association networks with increased coverage, supporting 
functional discovery in genome-wide experimental datasets. Nucleic Acids Res. 2019; 47: D607-d13.

22. Yu G, Wang LG, Han Y, He QY. clusterProfiler: an R package for comparing biological themes among gene clusters. Omics. 2012; 16: 284-7.

23. Gyorffy B, Lanczky A, Szallasi Z. Implementing an online tool for genome-wide validation of survival-associated biomarkers in ovarian-cancer using microarray data from 1287 patients. Endocr Relat Cancer. 2012; 19: 197208.

24. Lin SI, Huang MH, Chang YW, Chen IH, Roffler S, Chen BM, Sher YP, Liu SJ. Chimeric peptide containing both B and $T$ cells epitope of tumor-associated antigen $L 6$ enhances anti-tumor effects in HLA-A2 transgenic mice. Cancer Lett. 2016; 377: 126-33.

25. Gao C, Yao H, Liu H, Feng Y, Yang Z. TM4SF1 is a potential target for anti-invasion and metastasis in ovarian cancer. BMC Cancer. 2019; 19: 237.

26. Yeh YC, Lin HH, Tang MJ. Dichotomy of the function of DDR1 in cells and disease progression. Biochim Biophys Acta Mol Cell Res. 2019; 1866: 118473.

27. Quan J, Yahata T, Adachi S, Yoshihara K, Tanaka K. Identification of receptor tyrosine kinase, discoidin domain receptor 1 (DDR1), as a potential biomarker for serous ovarian cancer. Int J Mol Sci. 2011; 12: 971-82.

\section{Tables}

Table 1. Expression of TM4SF1 and DDR1 in ovarian cancer patients with different clinicopathologic features 


\begin{tabular}{|c|c|c|c|c|c|c|c|}
\hline Factors & $\mathrm{N}$ & $\begin{array}{l}\text { TM4SF1(+) } \\
{[\mathrm{n}(\%)]}\end{array}$ & $P$ & $\begin{array}{l}\text { DDR1(+) } \\
{[n(\%)]}\end{array}$ & $P$ & $\begin{array}{l}\text { TM4SF1(+)\&DDR1(+) } \\
\text { [n(\%)] }\end{array}$ & $P$ \\
\hline \multicolumn{8}{|l|}{ age } \\
\hline$\leq 50$ years & 46 & $27 \llbracket 58.70 \rrbracket$ & \multirow[t]{2}{*}{0.064} & $\begin{array}{l}26 \\
\otimes 56.52 \rrbracket\end{array}$ & \multirow[t]{2}{*}{0.818} & $16 \rrbracket 34.78 \rrbracket$ & \multirow[t]{2}{*}{0.131} \\
\hline$\bigotimes 50$ years & 48 & $19 \llbracket 39.58 \rrbracket$ & & $\begin{array}{l}26 \\
\otimes 50.00 \rrbracket\end{array}$ & & $10 \rrbracket 20.83 \rrbracket$ & \\
\hline \multicolumn{8}{|l|}{ histological grade } \\
\hline G1-2 & 20 & $11 \varangle 55.00 \rrbracket$ & \multirow[t]{2}{*}{0.541} & $6 \rrbracket 30.00 \rrbracket$ & \multirow[t]{2}{*}{0.010} & $5 \llbracket 25.00 \rrbracket$ & \multirow[t]{2}{*}{0.764} \\
\hline G3 & 74 & $35 \llbracket 47.30 \rrbracket$ & & $46(62.16)$ & & $21 \rrbracket 28.66 \rrbracket$ & \\
\hline \multicolumn{8}{|l|}{ FIGO stage } \\
\hline 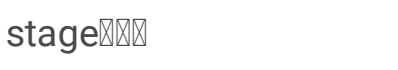 & 12 & $5 \rrbracket 41.67 \rrbracket$ & \multirow[t]{2}{*}{0.589} & $2 \otimes 16.67 \rrbracket$ & \multirow[t]{2}{*}{0.004} & $2 \otimes 16.67 \rrbracket$ & \multirow[t]{2}{*}{0.362} \\
\hline stage $\triangle \otimes \otimes$ & 82 & $41 \otimes 50.00 \rrbracket$ & & $50(60.98)$ & & $24 \llbracket 29.37 \rrbracket$ & \\
\hline \multicolumn{8}{|l|}{ pathological type } \\
\hline serous carcinoma & 82 & $37 \rrbracket 45.12 \rrbracket$ & \multirow[t]{2}{*}{0.053} & $47(57.32)$ & \multirow[t]{2}{*}{0.605} & $22 \llbracket 26.83 \rrbracket$ & \multirow[t]{2}{*}{0.638} \\
\hline non-serous carcinoma & 12 & $9 \otimes 75.00 \rrbracket$ & & $5(41.67)$ & & $4 \llbracket 33.33 \rrbracket$ & \\
\hline \multicolumn{8}{|c|}{ intraperitoneal metastasis } \\
\hline yes & 63 & $33 \llbracket 52.38 \rrbracket$ & \multirow[t]{2}{*}{0.341} & $\begin{array}{l}42 \\
866.67 \square\end{array}$ & \multirow[t]{2}{*}{0.002} & $20 \rrbracket 31.75 \rrbracket$ & \multirow[t]{2}{*}{0.207} \\
\hline no & 31 & $13 \llbracket 41.94 \rrbracket$ & & $\begin{array}{l}10 \\
\bigotimes 32.26 \rrbracket\end{array}$ & & $6 \rrbracket 19.35 \rrbracket$ & \\
\hline \multicolumn{8}{|l|}{$\begin{array}{l}\text { Neoadjuvant } \\
\text { chemotherapy }\end{array}$} \\
\hline yes & 56 & $25 \llbracket 44.62 \rrbracket$ & \multirow[t]{2}{*}{0.312} & $\begin{array}{l}32 \\
\otimes 57.14 \rrbracket\end{array}$ & \multirow[t]{2}{*}{0.666} & $14 \llbracket 25.00 \rrbracket$ & \multirow[t]{2}{*}{0.484} \\
\hline no & 38 & $21 \otimes 55.26 \rrbracket$ & & $\begin{array}{l}20 \\
\otimes 52.63 \bigotimes\end{array}$ & & $12 \varangle 31.58 \rrbracket$ & \\
\hline \multicolumn{8}{|l|}{ lymphatic metastasis $\boldsymbol{\Delta}$} \\
\hline yes & 25 & $13 \llbracket 52.00 \rrbracket$ & \multirow[t]{2}{*}{0.453} & $\begin{array}{l}15 \\
860.00 \rrbracket\end{array}$ & \multirow[t]{2}{*}{0.113} & $7 \rrbracket 28.00 \bigotimes$ & \multirow[t]{2}{*}{0.282} \\
\hline no & 31 & $13 \llbracket 52.00 \rrbracket$ & & $\begin{array}{l}12 \\
₫ 38.70 \rrbracket\end{array}$ & & $5 \rrbracket 16.13 \rrbracket$ & \\
\hline
\end{tabular}

note $\mathbb{\Delta}$ Comparisons were made in the 56 patients with resected lymph nodes.

Table 2 Univariate analysis of the correlation of clinicopathological factors with OS and PFS in ovarian cancer 


\begin{tabular}{|c|c|c|c|c|c|c|}
\hline \multirow[t]{2}{*}{ parameter } & \multicolumn{3}{|l|}{ OS } & \multicolumn{3}{|l|}{ PFS } \\
\hline & $\mathrm{HR}$ & $95 \% \mathrm{Cl}$ & $\mathrm{P}$ & $\mathrm{HR}$ & $95 \% \mathrm{Cl}$ & $\mathrm{P}$ \\
\hline age & 0.877 & $0.506 \rrbracket 1.520$ & 0.641 & 0.866 & $0.541 \otimes 1.385$ & 0.548 \\
\hline grade & 1.146 & $0.573 \llbracket 2.292$ & 0.700 & 1.387 & $0.742 \rrbracket 2.592$ & 0.305 \\
\hline stage & 6.860 & $1.650 \rrbracket 28.520$ & 0.008 & 2.999 & $1.287 \bowtie 6.990$ & 0.011 \\
\hline histological_type & 0.877 & $0.374 \rrbracket 2.057$ & 0.763 & 1.574 & $0.680 \otimes 3.640$ & 0.289 \\
\hline abdominal_invasion & 2.253 & $1.193 \rrbracket 4.257$ & 0.012 & 1.631 & $0.981 \otimes 2.711$ & 0.059 \\
\hline NACT & 1.750 & $0.953 \rrbracket 3.214$ & 0.071 & 1.565 & $0.946 \rrbracket 2.589$ & 0.082 \\
\hline lymph_node_excision & 0.617 & $0.355 \rrbracket 1.072$ & 0.087 & 0.628 & $0.390 \otimes 1.010$ & 0.055 \\
\hline TM4SF1 & 1.454 & $0.838 \rrbracket 2.525$ & 0.183 & 1.646 & $1.026 \rrbracket 2.642$ & 0.039 \\
\hline DDR1 & 2.324 & $1.271 \rrbracket 4.249$ & 0.006 & 1.555 & $0.962 \rrbracket 2.513$ & 0.072 \\
\hline TM4SF1\&DDR1 & 2.559 & $1.450 \rrbracket 4.517$ & 0.001 & 2.572 & $1.566 \rrbracket 4.224$ & 0.000 \\
\hline
\end{tabular}

NACT \neoadjuvant chemotherapy

Figures 
A

Gene expression profile across tumor samples and paired normal tissues

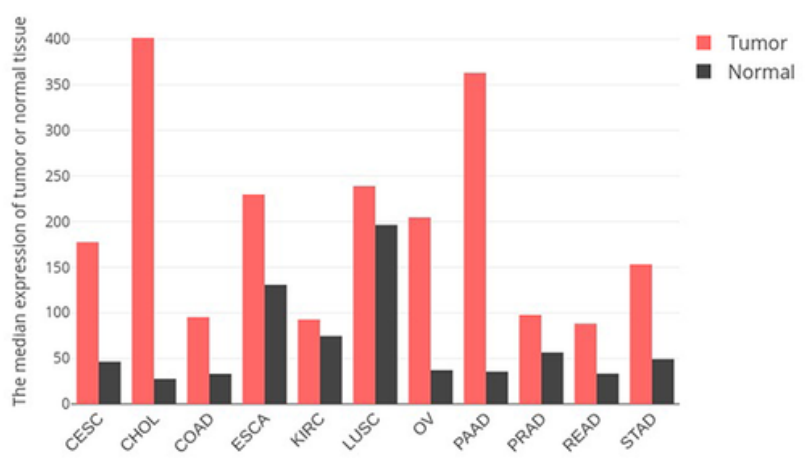

B

Gene expression profile across tumor samples and paired normal tissues

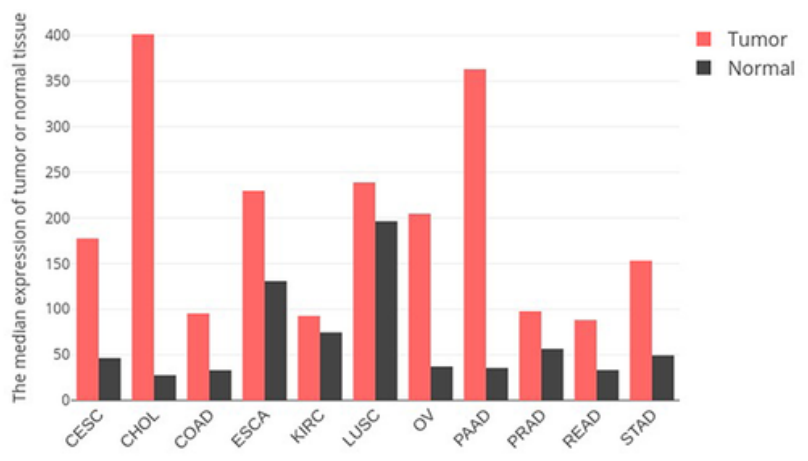

C

Disease Summary for TMASF1 (mRNA)

\begin{tabular}{|c|c|c|}
\hline \multirow{2}{*}{$\begin{array}{l}\text { Analysis Type by Cancer } \\
\text { Bladder Cancer }\end{array}$} & \multicolumn{2}{|c|}{$\begin{array}{c}\text { Cancer } \\
\text { vs. } \\
\text { Normal }\end{array}$} \\
\hline & 1 & 3 \\
\hline Brain and CNS Cancer & 10 & 3 \\
\hline Breast Cancer & & 15 \\
\hline Cervical Cancer & 1 & 3 \\
\hline Colorectal Cancer & 16 & \\
\hline Esophageal Cancer & 3 & 3 \\
\hline Gastric Cancer & 1 & \\
\hline Head and Neck Cancer & 5 & 2 \\
\hline Kidney Cancer & 3 & 6 \\
\hline Leukemia & 3 & 4 \\
\hline Liver Cancer & 7 & \\
\hline Lung Cancer & 1 & 6 \\
\hline Lymphoma & 10 & 1 \\
\hline Melanoma & & 2 \\
\hline Myeloma & & \\
\hline Other Cancer & 6 & 2 \\
\hline Ovarian Cancer & 1 & \\
\hline Pancreatic Cancer & 3 & \\
\hline Prostate Cancer & 3 & 1 \\
\hline Sarcoma & 1 & 8 \\
\hline Significant Unique Analyses & 75 & 58 \\
\hline Total Unique Analyses & 37 & \\
\hline
\end{tabular}

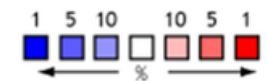

D

Disease Summary for DDR1 (mRNA)

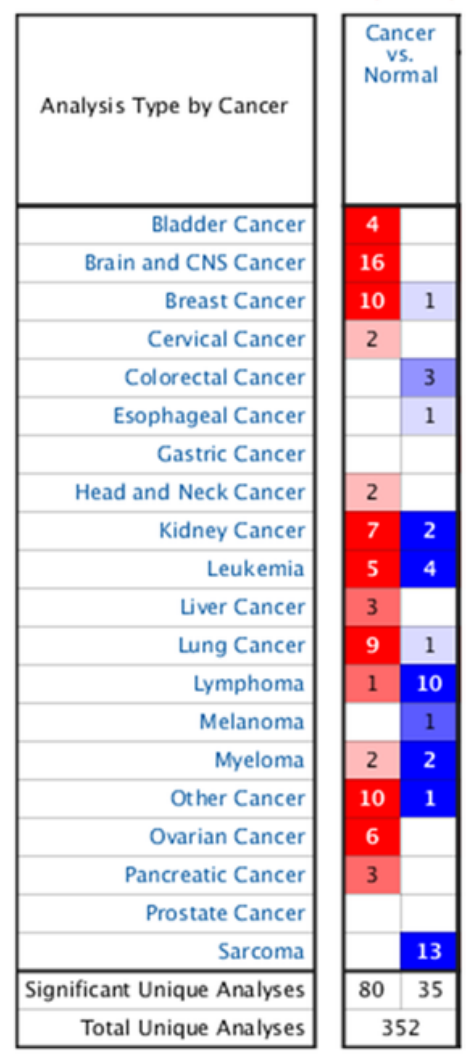

$\begin{array}{llllll}1 & 5 & 10 & 10 & 5 & 1\end{array}$

Figure 1

The biological functions and roles of TM4SF1 and DDR1 in cancer are still unclear. To reveal their roles in tumorigenesis and development, differentially expressed genes were identified. The results showed that TM4SF1 and DDR1 were highly expressed in a variety of common malignant tumours 
A

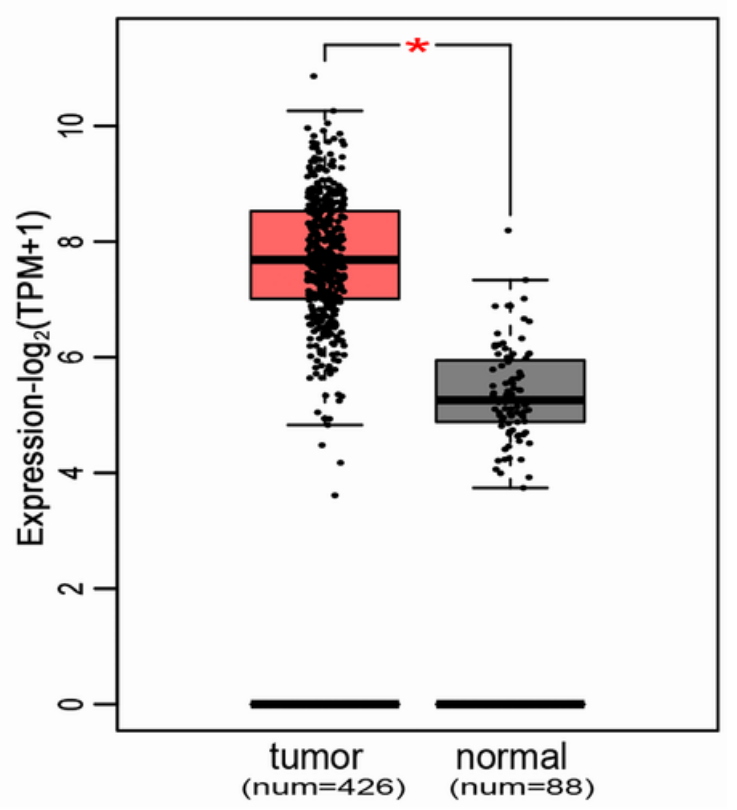

C

Comparison of TM4SF1 Across 10 Analyses Over-expression

\begin{tabular}{|c|c|c|c|c|c|c|c|c|c|c|c|c|}
\hline Median Rank & p-Value & Gene & & & & & & & & & & \\
\hline \multirow[t]{2}{*}{2408.5} & 0.004 & TM4SF 1 & & & & & & & & & & \\
\hline & & & 1 & 2 & 3 & 4 & 5 & 6 & 7 & 8 & 9 & 10 \\
\hline
\end{tabular}

Legend

1. Ovarian Serous Adenocarcinoma vs. Normal 6. Ovarian Serous Adenocarcinoma vs. Normal Adib Ovarian, Br J Cancer, 2004

2. Ovarian Carcinoma vs. Normal Bonome Ovarian, Cancer Res, 2008

3. Ovarian Clear Cell Adenocarcinoma vs. Normal

Hendrix Ovarian, Cancer Res, 2006

4. Ovarian Endometrioid Adenocarcinoma vs. Normal

Hendrix Ovarian, Cancer Res, 2006

5. Ovarian Mucinous Adenocarcinoma vs. Normal

Hendrix Ovarian, Cancer Res, 2006
Hendrix Ovarian, Cancer Res, 2006

7. Ovarian Endometrioid Adenocarcinoma vs. Normal

Lu Ovarian, Clin Cancer Res, 2004

8. Ovarian Serous Adenocarcinoma vs. Normal Lu Ovarian, Clin Cancer Res, 2004

9. Ovarian Serous Cystadenocarcinoma vs.

10. Ovarian Serous Surface Papillary Carcinoma vs. Normal

Welsh Ovarian, Proc Natl Acad Sci U S A, 2001 TCGA Ovarian, No Associated Paper, 2013

B

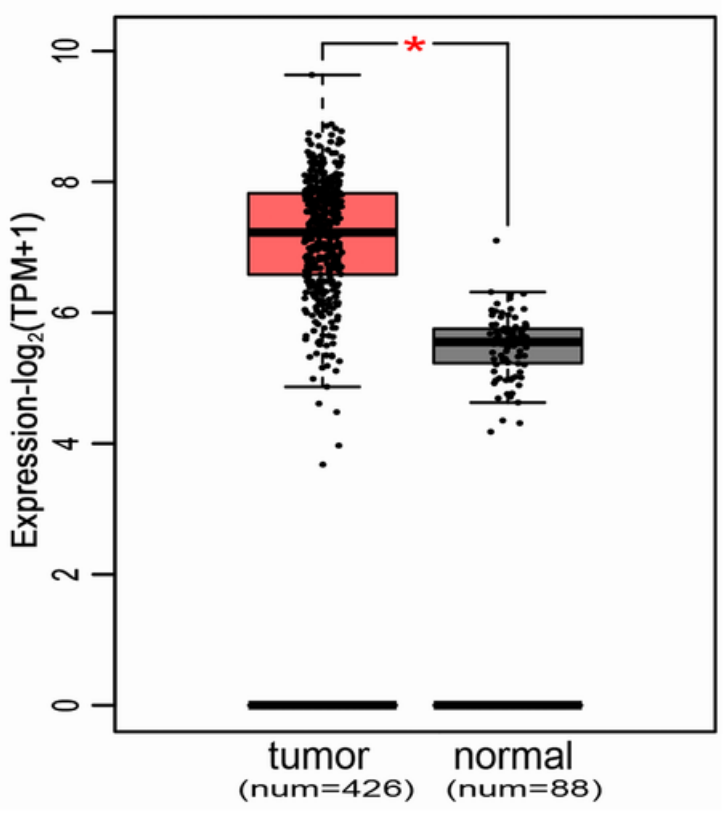

D

\begin{tabular}{|c|c|c|c|c|c|c|c|c|c|c|c|c|}
\hline & npariso & n of D & R1 & $\begin{array}{l}\mathrm{AC} \\
\text { press }\end{array}$ & $\begin{array}{l}\text { sos } \\
\text { sion }\end{array}$ & & 0 & Ana & S & & & \\
\hline Median Rank & p-Value & Gene & & & & & & & & & & \\
\hline 153.0 & $3.22 \mathrm{E}-4$ & DDR1 & & & & & & & & & & \\
\hline & & & 1 & 2 & 3 & 4 & 5 & 6 & 7 & 8 & 9 & 10 \\
\hline
\end{tabular}

Legend

1. Ovarian Serous Adenocarcinoma vs. Normal 6. Ovarian Serous Adenocarcinoma vs. Normal Adib Ovarian, Br J Cancer, $2004 \quad H e n d r i x$ Ovarian, Cancer Res, 2006

2. Ovarian Carcinoma vs. Normal Bonome Ovarian, Cancer Res, 2008

3. Ovarian Clear Cell Adenocarcinoma vs. Normal

Hendrix Ovarian, Cancer Res, 2006

4. Ovarian Endometrioid Adenocarcinoma vs. Normal

Hendrix Ovarian, Cancer Res, 2006

5. Ovarian Mucinous Adenocarcinoma vs. Normal

Hendrix Ovarian, Cancer Res, 2006

7. Ovarian Endometrioid Adenocarcinoma vs. Normal

Lu Ovarian, Clin Cancer Res, 2004

8. Ovarian Serous Adenocarcinoma vs. Normal Lu Ovarian, Clin Cancer Res, 2004

9. Ovarian Serous Surface Papillary Carcinoma vs. Normal

Welsh Ovarian, Proc Natl Acad Sci U S A, 2001

10. Ovarian Serous Adenocarcinoma vs. Normal

Yoshihara Ovarian, Cancer Sci, 2009

$\begin{array}{llllllll}1 & 5 & 10 & 25 & 25 & 10 & 5 & 1\end{array}$

The rank for a gene is the median rank for that gene across each of the analyses.
The p.Value for a gene is its p.Value for the median-ranked analysis.

\section{Figure 2}

GEPIA analysis showed that TM4SF1 and DDR1 were significantly higher in ovarian cancer than in normal ovaries (both $\mathrm{P} \otimes 0.05$ ). A meta-analysis of the Oncomine database (including 10 analyses of 7 ovarian cancer datasets) also showed that TM4SF1 and DDR1 were significantly more highly expressed in ovarian cancer than in normal ovarian tissue (TM4SF1: $P=0.004$; DDR1: $P=3.22 E-4)$ 


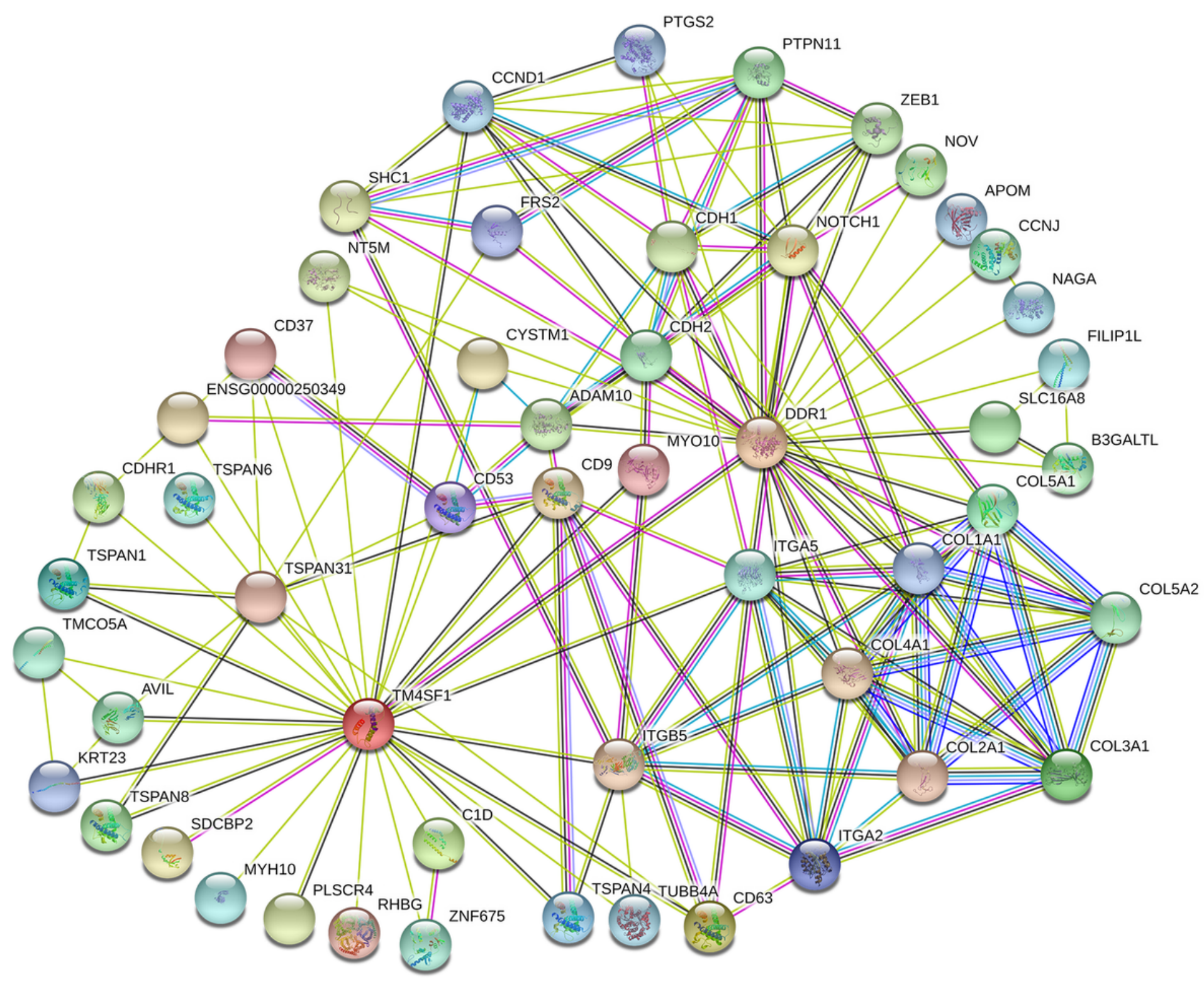

Figure 3

The top 50 proteins that directly interact with TM4SF1 and DDR1 were queried by the STRING online tool, and 28 and 25 proteins were found to interact with TM4SF1 and DDR1, respectively. Among these interacting proteins, both CYSTM1 and NT5M interacted with TM4SF1 and DDR1, and TM4SF1 also interacted with DDR1 


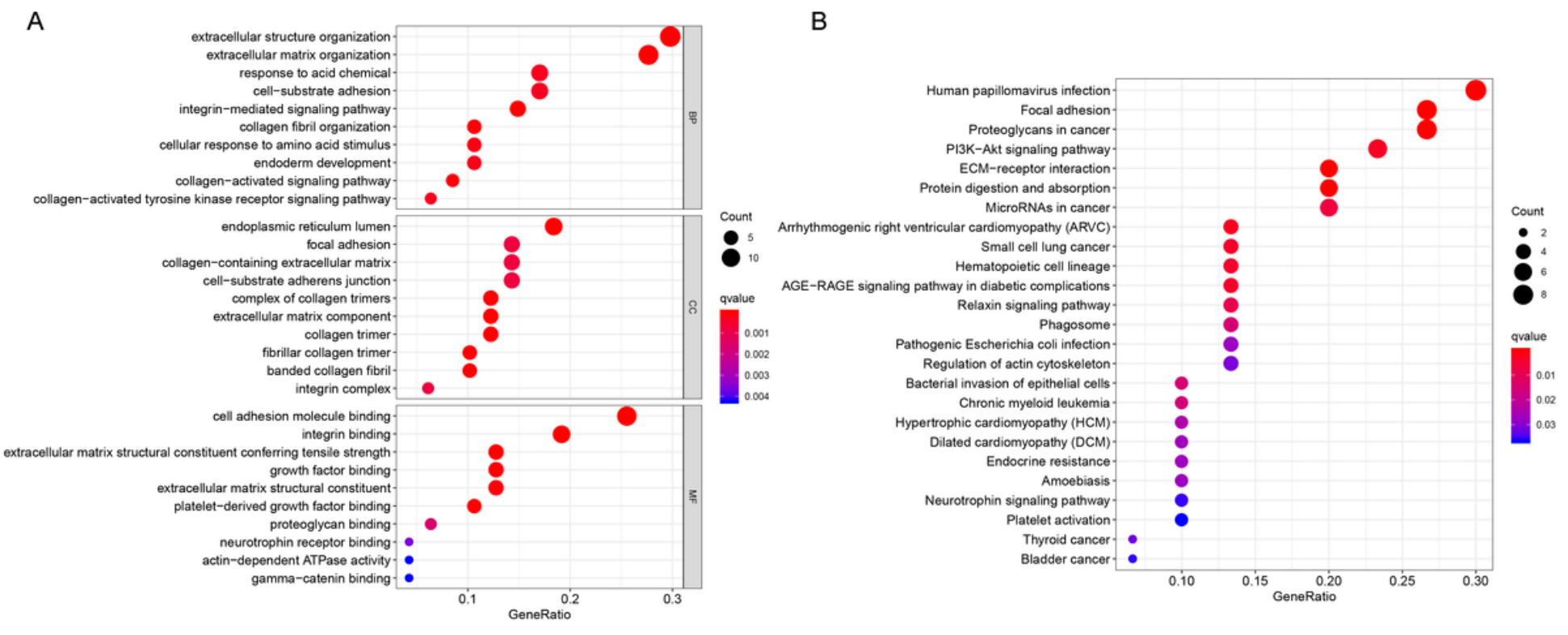

\section{Figure 4}

GO enrichment analysis of the interacting proteins showed that they were mainly involved in the composition of ECM, collagen, integrin and their complexes as well as adhesion spots, endoplasmic reticulum and other intracellular and extracellular components. GO enrichment analysis also indicated that these interacting proteins had the molecular function of binding with integrin, cell adhesion molecules, growth factors, proteoglycans, neurotrophic factor receptors and $\gamma$-catenin. GO analysis also showed that they were mainly involved in cell-matrix adhesion and cell response to amino acid stimulation, and it indicated that they played biological functions by activating integrin and collagen-mediated signalling pathways 
TM4SF1

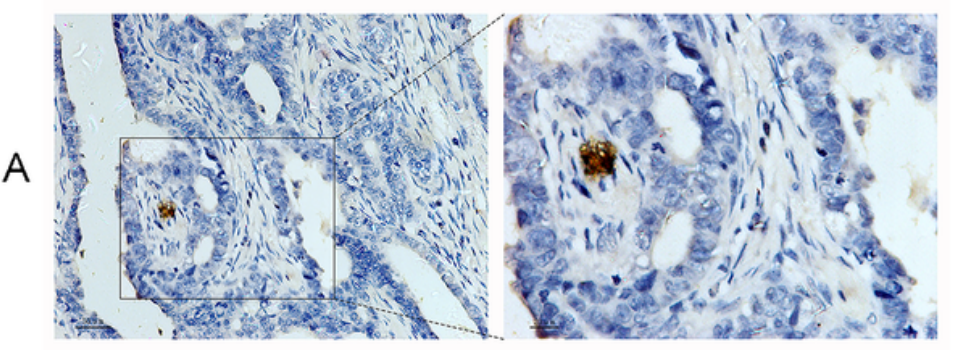

B

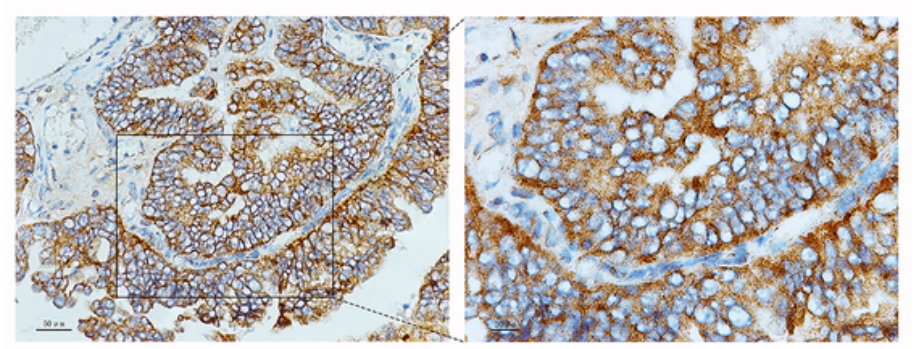

C

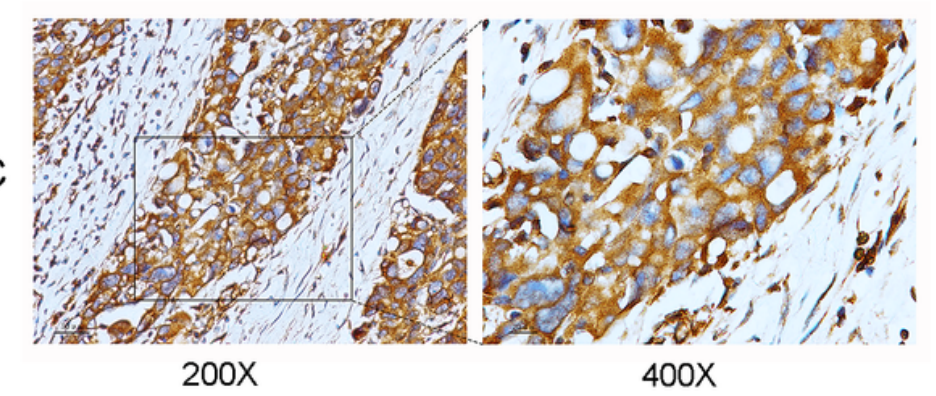

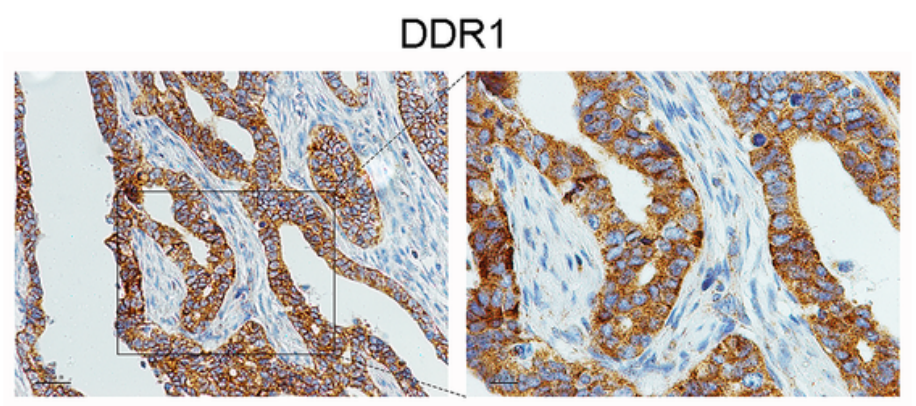
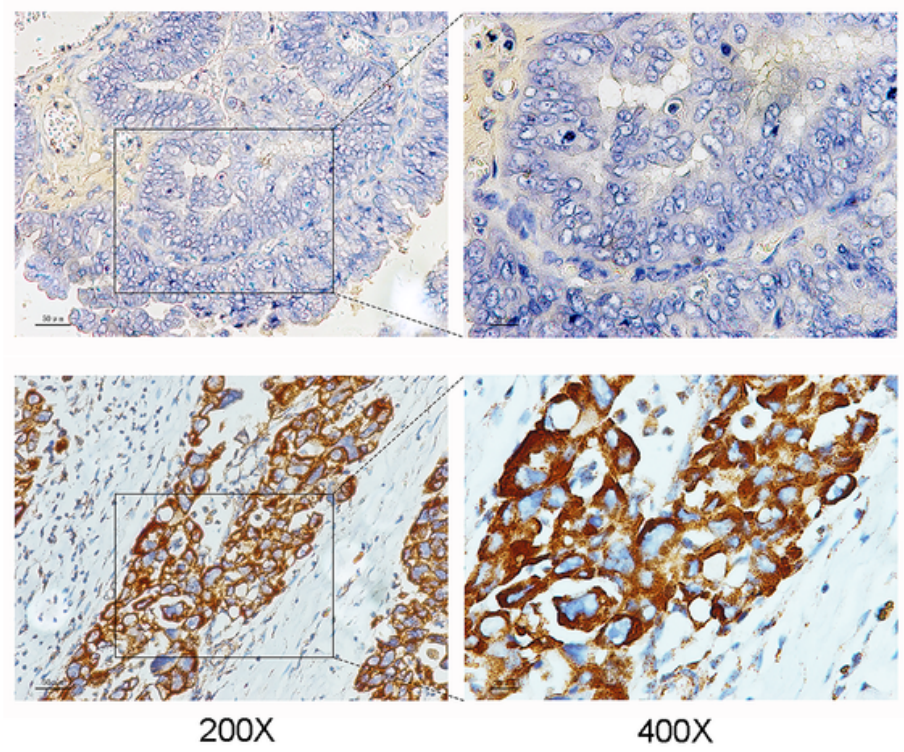

\section{Figure 5}

A total of 94 patients with epithelial ovarian cancer were included, and the patient age ranged from 28 to 83 years old with a median age of 51 years. A total of 56 patients received neoadjuvant chemotherapy. The results showed that 46 patients (48.94\%) were positive for TM4SF1 protein, and 52 patients $(55.32 \%)$ were positive for DDR1 protein. In addition, 26 patients (27.66\%) were positive for both TM4SF1 and DDR1 protein. The staining of TM4SF1 and DDR1 proteins in ovarian cancer tissues 
A

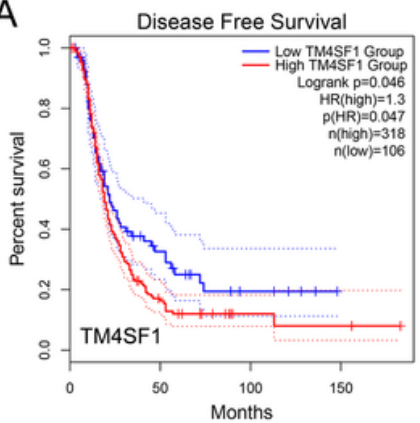

E

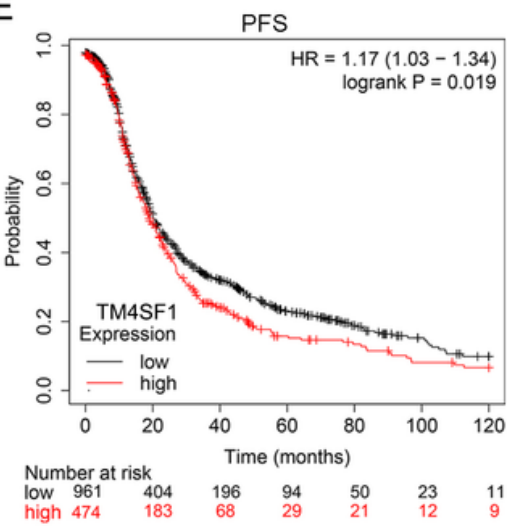

$\mathrm{H}$

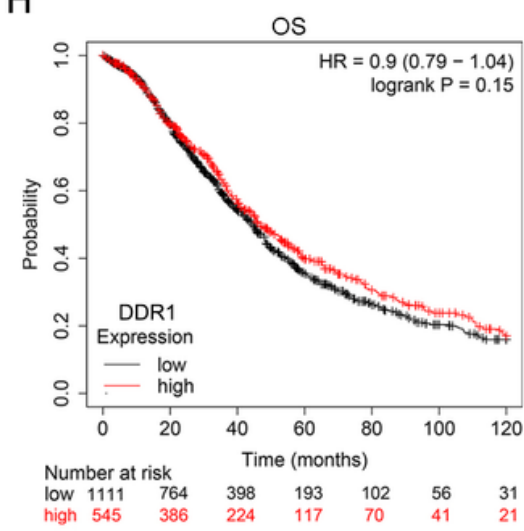

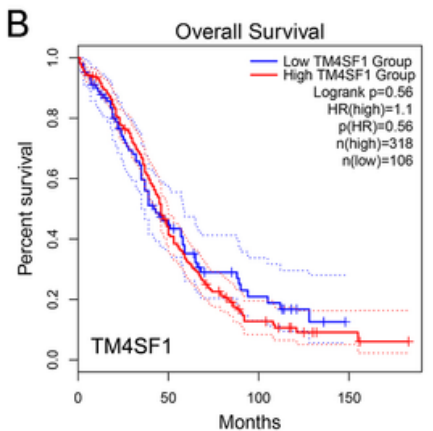

C

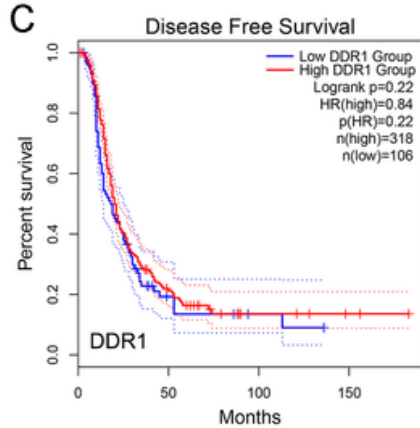

D

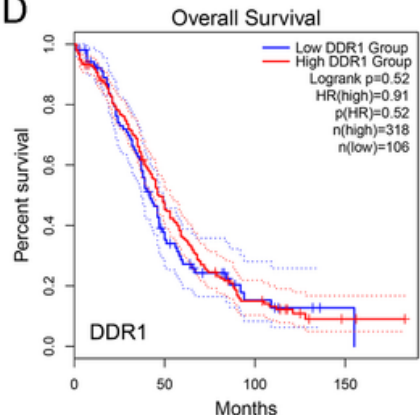

F

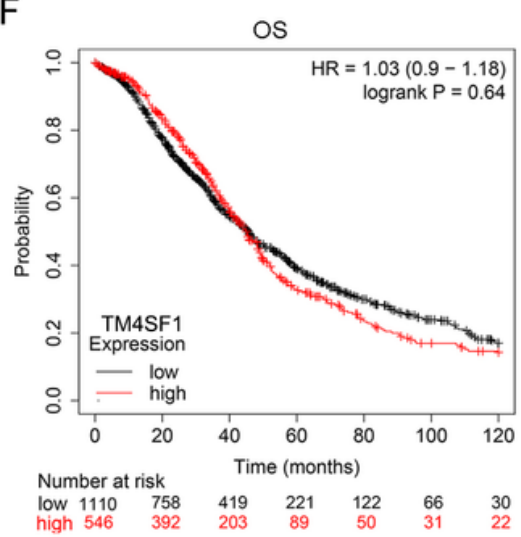

I

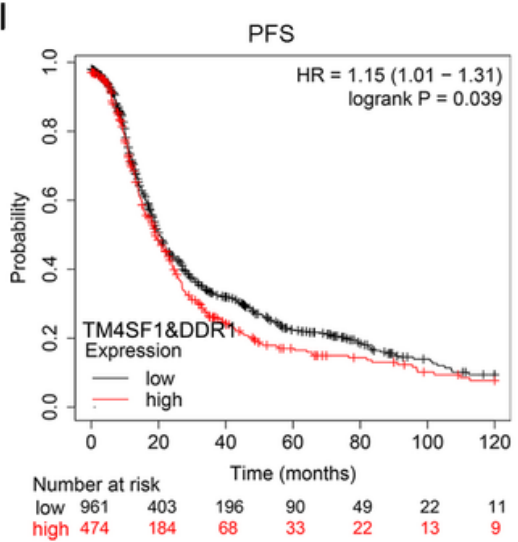

G

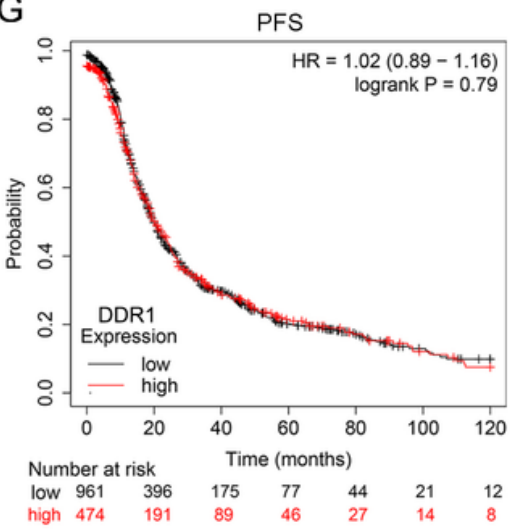

J

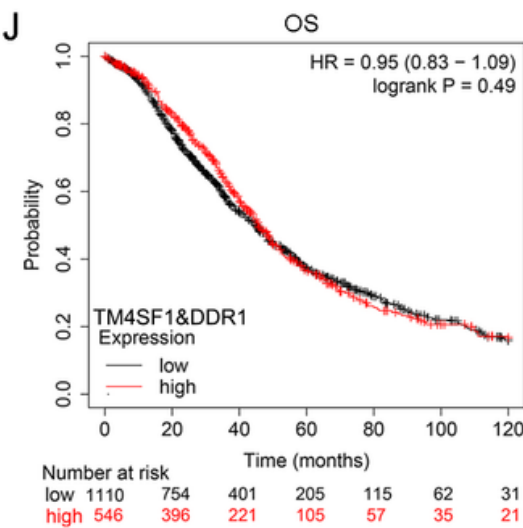

\section{Figure 6}

Biological database analysis showed that ovarian cancer patients with high expression of TM4SF1 had significantly lower disease-free survival(DFS) or PFS than those with low expression (DFS: HR=1.3, $P=0.046, n=424$, Figure 6A; PFS: $H R=1.17, P=0.019, N=1435$, Figure $6 E$ ). In addition, the expression of DDR1 had no correlation with patient DFS or PFS, and the expression of TM4SF1 and DDR1 had no significant correlation with patient OS (Figure 6B-D, Figure 6F-H). However, KM plotter multigene analysis showed that higher expression of TM4SF1 and DDR1 was significantly associated with shorter PFS of patients with ovarian cancer $(H R=1.15, P=0.039, n=1435$, Figure 6I) but not with OS (Figure 6J). 
A

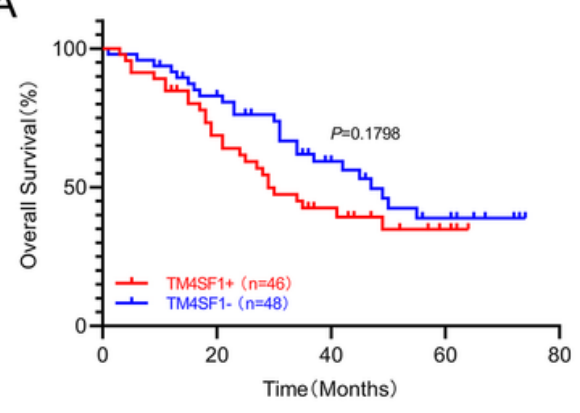

D

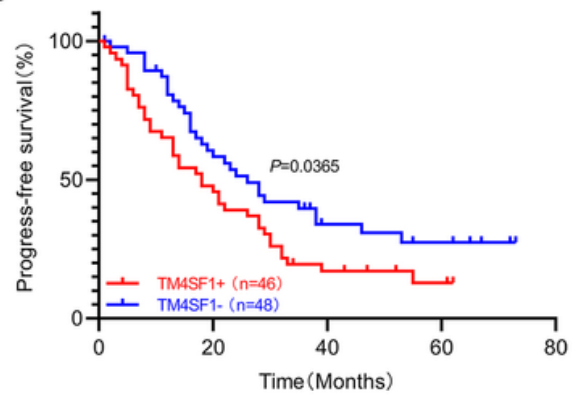

B

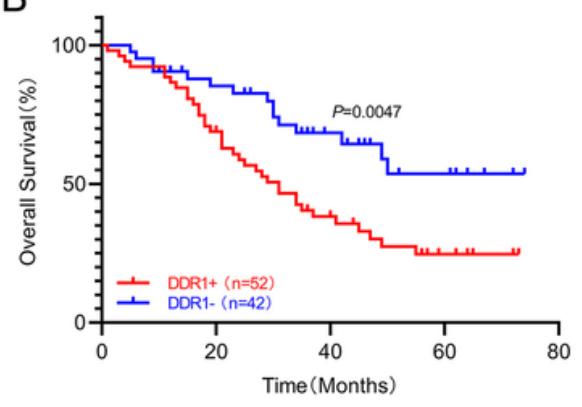

E

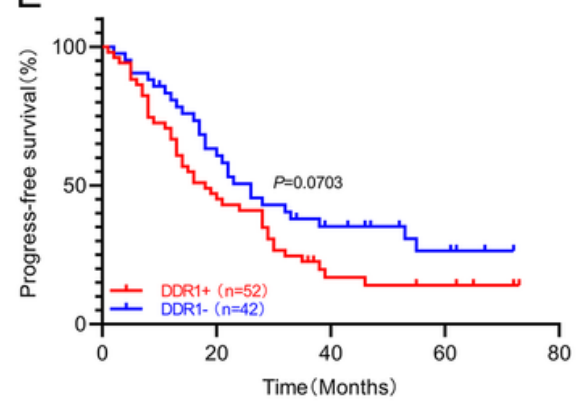

C

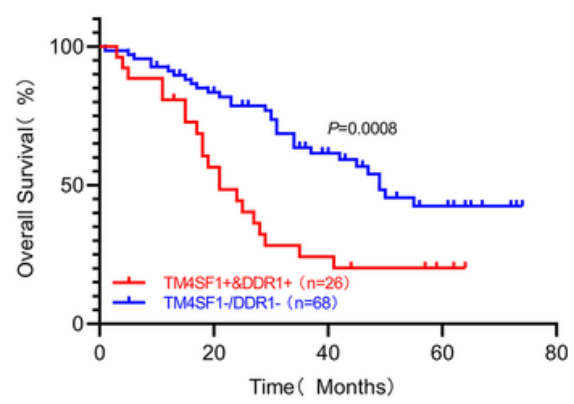

F

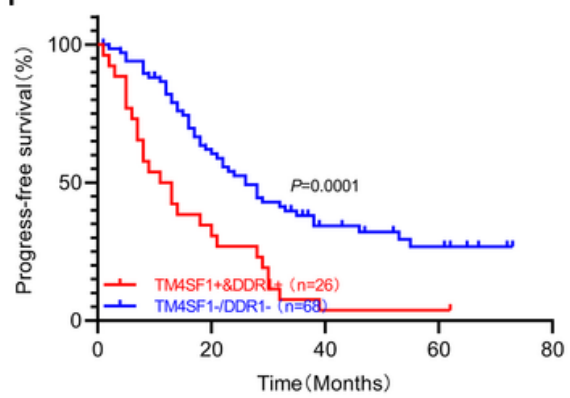

\section{Figure 7}

The median OS of patients with TM4SF1 and DDR1 coexpression was significantly shorter than that of patients lacking TM4SF1 and DDR1 coexpression (21 vs. 49 months, $\mathrm{P}<0.05)$. In addition, the median PFS of TM4SF1positive patients was significantly shorter than that of TM4SF1-negative patients (18 vs. 26 months, $P<0.05$ ). The median PFS of patients with TM4SF1 and DDR1 coexpression was significantly shorter than that of patients lacking TM4SF1 and DDR1 coexpression (12 vs. 26 months, $P<0.05$ ), while the expression of DDR1 was not related to the median PFS $(P>0.05)$

A

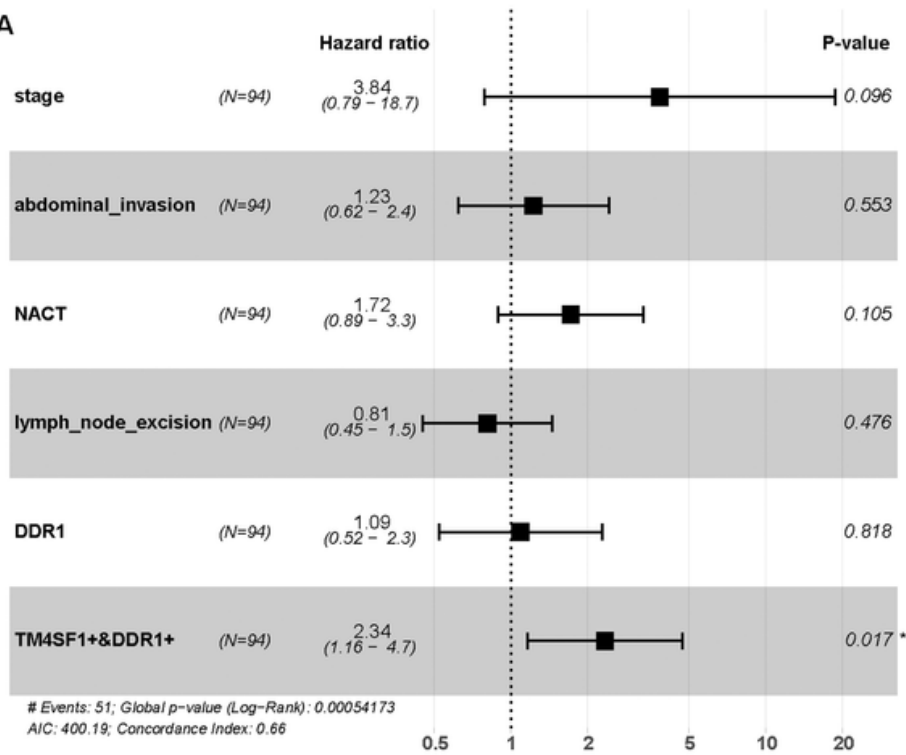

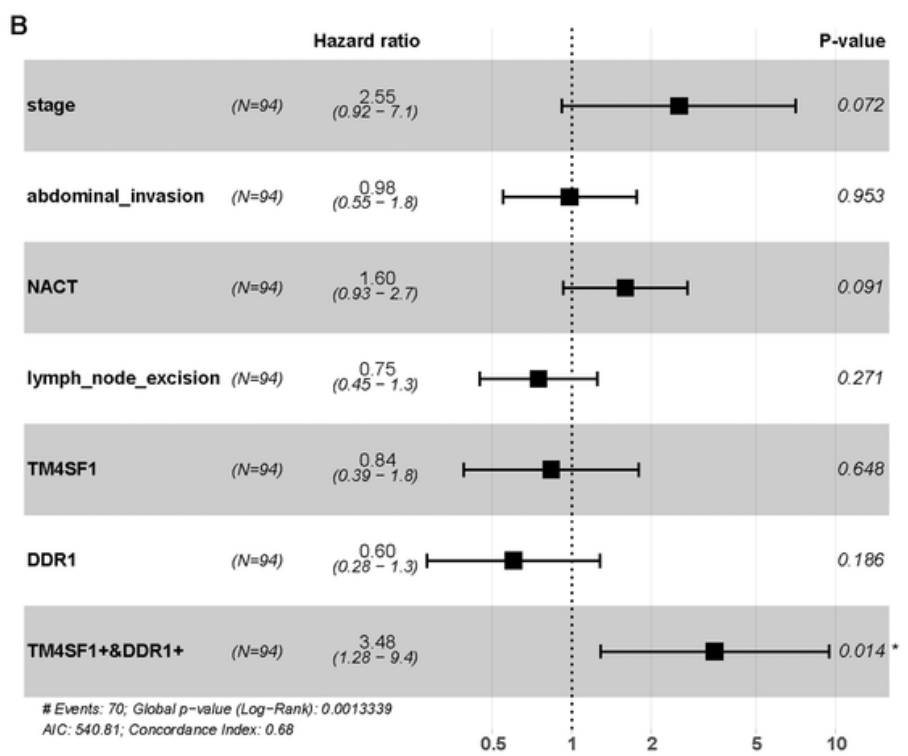

\section{Figure 8}


Cox multivariate analysis showed that TM4SF1 and DDR1 coexpression was the only independent risk factor affecting OS and PFS in ovarian cancer patients

\section{Supplementary Files}

This is a list of supplementary files associated with this preprint. Click to download.

- Supplementary.docx 